01,13

\title{
Влияние относительного содержания металлической компоненты в диэлектрической матрице на образование и размеры нанокристаллов кобальта в пленочных композитах $\mathrm{Co}_{x}\left(\mathrm{MgF}_{2}\right)_{100-x}$
}

\author{
(C) Э.П. Домашевская ${ }^{1}$, С.А. Ивков ${ }^{1}$, А.В. Ситников ${ }^{2}$, О.В. Стогней ${ }^{2}$, \\ А.Т. Козаков ${ }^{3}$, А.В. Никольский ${ }^{3}$
}

${ }^{1}$ Воронежский государственный университет, Воронеж, Россия

${ }^{2}$ Воронежский государственный технический университет,

Воронеж, Россия

${ }^{3}$ Южный федеральный университет,

Ростов-на-Дону, Россия

E-mail: ft@@phys.vsu.ru

(Поступила в Редакцию 8 августа 2018 г.)

Методами рентгеновской дифракции (XRD), рентгеноэлектронной спектроскопии (XPS) и инфракрасной спектроскопии (ИК) установлено влияние относительного содержания металлической компоненты на фазовый состав и субструктуру нанокомпозитов $\mathrm{Co}_{x}\left(\mathrm{MgF}_{2}\right)_{100-x}$ в широком интервале изменения значений $x=16-63$ at.\%. Слои нанокомпозитов микронной толщины получали ионно-лучевым распылением составной мишени в атмосфере аргона.

Полученные результаты показывают, что относительное содержание металлического кобальта Со в диэлектрической матрице $\mathrm{MgF}_{2}$ самым существенным образом влияет на фазовый состав и субструкуру нанокомпозитов.

При меньшем содержании металлической фазы кобальт находится в рентгеноаморфном состоянии в виде кластеров в объеме нанокристаллической матрицы $\mathrm{MgF}_{2}$. С увеличением содержания кобальта до $x=29$ at. $\%$ на ситаловой подложке и до $x=42$ at.\% на стеклянной подложке в рентгеноаморфной диэлектрической матрице $\mathrm{MgF}_{2}$ формируются нанокристаллы кобальта гексагональной сингонии размерами порядка $10 \mathrm{~nm}$, преимущественно ориентированные в плоскости базиса гексагональной решетки $(001) \alpha$-Со. При дальнейшем возрастании содержания кобальта до $c=59$ at.\% размеры нанокристаллов $\alpha$-Со достигают $\sim 20 \mathrm{~nm}$ с сохранением той же преимущественной ориентации.

Тонкая структура XPS-спектров Co $2 p$ и O $1 s$ показала, что на поверхности композитов кобальт сильно окислен во всех образцах и только на поверхности образцов с малым содержанием Со наряду с оксидом кобальта обнаруживается мелкодисперсный, рентгеноаморфный кобальт в металлическом состоянии.

На ИК-спектрах этих же образцов с наименьшим содержанием металлической фазы наблюдается наиболее четкое формирование мод от нанокристаллической диэлектрической матрицы $\mathrm{MgF}_{2}$

Работа выполнена при поддержке Минобрнауки России в рамках государственного задания ВУЗам в сфере научной деятельности на 2017-2019 годы. Проект № 3.6263.2017/ВУ.

DOI: 10.21883/FTT.2019.02.47115.211

\section{1. Введение}

Обнаружение гигантского магнетосопротивления (ГМС) в разнообразных материалах, содержащих $3 d$-металлы, привели к значительному прогрессу в технологиях их изготовления и использования в различных электронных устройствах. В соответствии с механизмом ГМС подобные материалы делятся на две категории. Во-первых, металлические многослойные структуры (МНC) [1] и металлические наногранулированные сплавы $[2,3]$ в которых ГМС является результатом спин-зависимого рассеяния электронов [4]. Во-вторых, МНС из слоев металл/диэлектрик [5,6] и композитные наногранулированные пленки металл-диэлектрик $[7,8]$ в которых ГМС является результатом спин-зависимого туннелирования электронов, т.е. является туннельным магнетосопротивлением (ТMC) [9].

Композитные пленки, состоящие из магнитных металлических наногранул, равномерно распределенных в диэлектрической матрице, и обладающие анизотропным ТМС, являются перспективными материалами СВЧ-электроники и спинтроники [10]. Магнитные свойства таких гетерофазных систем зависят от многих параметров атомного и электронного строения компонент. К основным относится соотношение объемов ферромагнитной и немагнитной фаз, влияющее на расстояния между наночастицами металлического сплава и, следовательно, на величину магнитного взаимодействия между магнитными моментами гранул. Важным параметром, влияющим на свойства гранулированных композитов, является размер металлических гранул, который 
контролируется условиями получения и объемной долей металла $\left(x_{v}\right)$.

В качестве матриц гранулированных композитов чаще всего используются оксидные диэлектрики $\mathrm{SiO}_{2}, \mathrm{Al}_{2} \mathrm{O}_{3}$, $\mathrm{MgO}, \mathrm{HfO}_{2}, \mathrm{ZrO}_{2}$ и т.д. Для композитов с малой величиной $x_{v}$ металлические гранулы изолированы друг от друга в объеме матрицы, и поэтому такие среды близки по своим свойствам к изоляторам. С другой стороны, для составов с большой величиной $x_{v}$ реализуется металлический режим проводимости. При этом размеры и количество гранул в единице объема возрастают настолько, что происходит формирование проводящих кластеров и сплошных металлических каналов (цепочек или „сеток“ из взаимно контактирующих друг с другом гранул), пронизывающих весь материал и обеспечивающих преимущественно металлический тип проводимости [10,11].

Протяженная проводящая „сетка“ и магнитная замкнутая структура возникает в композитах при достижении так называемого перколяционного предела (порога протекания). Экспериментально установлено, что для большого количества гранулированных композитов порог протекания соответствует $x_{v}$, равному 0.5-0.6 [10]. Для большинства общеизвестных металлов, таких как $\mathrm{Fe}, \mathrm{Co}, \mathrm{Au}, \mathrm{Cu}$ и т. д. гранулы могут иметь размер от одного до нескольких десятков нанометров. Это та область размеров, в которой ферромагнитные гранулы становятся однодоменными и возможен переход в суперпарамагнитное состояние.

Гранулированные композиты могут быть получены различными методами, однако ионное распыление является наиболее универсальным [10,11]. Формирование гранулированной структуры происходит на поверхности подложки, куда осаждаются атомы или атомные комплексы, выбитые из мишени. Разделение конденсирующейся среды на две компоненты (диэлектрическая и металлическая) осуществляется в результате процессов самоорганизации, движущей силой которых является стремление к снижению энтропии при реализации нестационарного процесса, которым является конденсация из газовой фазы [11].

Большинство известных композитных систем получено на основе оксидных диэлектриков. Следствием этого является существенное окисление поверхности металлических гранул, что сказывается на магнитных и особенно на ВЧ-характеристиках композитов. В связи с этим, интерес вызывают композиты, не содержащие в своем номинальном составе кислород. Так, например, в работе [12] были получены наногранулированные тонкие пленки, состоящие из гранул $\mathrm{Fe}$ или сплава $\mathrm{Fe}_{51} \mathrm{Co}_{49}$, распределенных в диэлектрической матрице $\mathrm{MgF}_{2}$, которые обнаруживают гигантское магнетосопротивление при комнатной температуре. В другой работе [13] были исследованы тонкопленочные $(200 \mathrm{~nm})$ нанокомпозитыг $\left(\mathrm{Fe}_{65} \mathrm{Co}_{35}\right)_{x}\left(\mathrm{MgF}_{2}\right)_{100-x}$, полученные высокочастотным магнетронным распылением составной мишени в атмосфере Ar при двух разных мощностях распыления 60 и $200 \mathrm{~W}$. Результаты этих исследований показали, что высокая мощность распыления приводит к формированию FeCo-фторидов, которые ухудшают магнитомягкие свойства композитов, тогда как образцы, напыленные при мощности $60 \mathrm{~W}$, проявляют хорошие магнитомягкие свойства в широком диапазоне значений $x=55-90$ at.\%. Высокая химическая активность фтора позволяет формировать достаточно необычные диэлектрические фазы. Например, в [1] приводятся данные о системе $\mathrm{Co}_{x}\left(\mathrm{CaF}_{2}\right)_{100-x}$, в которой присутствует отрицательное магнитосопротивление, однако отсутствует положительный магниторезистивный эффект, характерный для систем $\mathrm{Co}-\mathrm{SiO}_{2}$ [14] и $\mathrm{Co}-\mathrm{Al}_{2} \mathrm{O}_{3}$ [15]. Данная особенность связывается либо с очень низким значением поверхностной энергии $\mathrm{CaF}_{2}$ по сравнению с кобальтом, в результате чего диэлектрическая фаза „обволакивает“ гранулы кобальта, препятствуя формированию перколяционных кластеров, либо с образованием диэлектрической оболочки $\mathrm{CoF}_{2}$ на поверхности наногранул кобальта.

Объектом исследования настоящей работы является аналогичная система $\mathrm{Co}_{x}\left(\mathrm{MgF}_{2}\right)_{100-x}$ с моноэлементной ферромагнитной фазой из кобальта и диэлектрической матрицей из фторида магния. Цель работы - установить влияние относительного содержания металлической компоненты в диэлектрической матрице на образование и размеры нанокристаллов кобальта и определить особенности фазообразования, структуры и субструктуры гранулированных нанокомпозитов $\mathrm{Co}_{x}\left(\mathrm{MgF}_{2}\right)_{100-x}$ в зависимости от соотношения фаз, с помощью рентгеновской дифракции (XRD), рентгеноэлектронной спектроскопии (XPS) и инфракрасной IR-спектроскопии.

\section{2. Объекты и методы исследования}

Исследованные в работе наногранулированные композитные пленки с различным содержанием металлической $(\mathrm{Co})$ и диэлектрической $\left(\mathrm{MgF}_{2}\right)$ компонент получены на оригинальной установке ионно-лучевого напыления [16]. Оптимальным вариантом обеспечения идентичных условий получения композитов является формирование композитов с разным соотношением диэлектрической и металлической фаз в одном процессе осаждения. Такой вариант реализован при распылении составной мишени с неравномерным и несимметричным размещением металлической и диэлектрической частей, в результате чего в напыляемом материале формируется заданный градиент концентраций. Мишень представляла собой прямоугольную литую основу $270 \times 70 \times 14 \mathrm{~mm}$ металлического Со с расположенными на ее поверхности пластинами диэлектрика $\mathrm{MgF}_{2}$ одинакового размера, но на различном расстоянии друг от друга. Не эквидистантное размещение диэлектрических пластин на поверхности металлической мишени является принципиальной особенностью данного способа. Поскольку в используемой установке расстояние мишень-подложка $(200 \mathrm{~mm})$ значительно больше, чем ширина диэлек- 
трической пластины $(10 \mathrm{~mm})$ или максимальное расстояние между соседними пластинами, распределение каждого компонента мишени по поверхности подложки оказывается монотонным с градиентом, определяемым конфигурацией расположения пластин.

Распыление мишени осуществлялось в атмосфере аргона на подложки из ситалла и стекла. Оказалось, что рентгенодифракционный анализ фазового состава и субструктуры удобнее проводить с образцами на стеклянных подложках, а рентгеноэлектронные исследования химического состояния поверхностных слоев композитов - с образцами на ситаловых подложках. Для исследования влияния состава композитов на его субструктуру были получены описанным способом композиты $\mathrm{Co}_{x}\left(\mathrm{MgF}_{2}\right)_{100-x}$ с металлическим кобальтом в диэлектрической матрице $\mathrm{MgF}_{2}$ в интервале изменений $x=14-63$ at.\%, включающем порог перколяции. Толщины получаемых таким образом слоев гранулированных композитов варьировались в пределах $2-4 \mu \mathrm{m}$.

Измерение концентраций химических элементов, входящих в состав композитов, проводилось методом электронно-зондового рентгеноспектрального микроанализа на приставке сканирующего микроскопа JEOL JSM-6380LV (ЦКП НО ВГУ), оснащенной тремя кристалл-дифракционными спектрометрами и системой энергодисперсионного анализа, с погрешностью, не превышающей $1.5 \%$ от содержания измеряемого элемента. Определяемый состав композитного слоя отражал содержание химического элемента, выраженное в атомных процентах.

$\mathrm{XRD}$-исследования проводились на дифрактометре ДРОН-4 с СоK-излучением в режиме пошагового сканирования. XPS-спектры остовных уровней элементов в нанокомпозитах разного состава были получены в сверхвысоком вакууме с использованием послойного ионного травления поверхности образцов на приборе ESCALAB 250 НИИ физики ЮФУ.

ИК-спектры композитов $\mathrm{Co}_{x}\left(\mathrm{MgF}_{2}\right)_{100-x}$ снимались на инфракрасном Фурье-спектрометре VERTEX 70 фирмы BRUKER (ЦКП НО ВГУ), в ИК-диапазоне $400-4000 \mathrm{~cm}^{1}$ Регистрация ИК-спектров на отражение производилась методикой НПВО - нарушенного полного внутреннего отражения.

\section{3. Результаты и их обсуждение}

\section{1. Дифрактометрические исследования фазового состава композитов $\mathrm{Co}_{x}\left(\mathrm{MgF}_{2}\right)_{100-x}$}

На рис. 1 и 2 приведены репрезентативные дифрактограммы образцов разного состава, полученных на подложках из ситала (рис. 1) и стекла (рис. 2), с интервалом изменения содержания металлической компоненты Со около $\Delta x \sim 10$ at.\% в порядке возрастания содержания металлического кобальта в композите $\mathrm{C}_{x}\left(\mathrm{MgF}_{2}\right)_{100-x}$.
Справа от каждой дифрактограммы на рисунках приведено содержание металлического кобальта Со в атомных процентах в составе композита по данным микроанали-

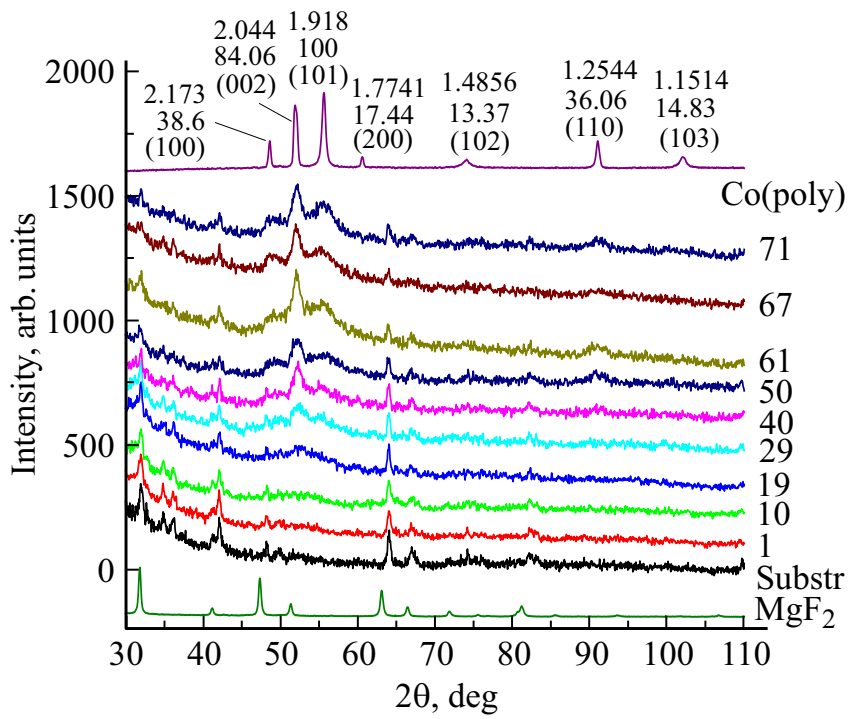

Рис. 1. Дифрактограммы от образцов нанокомпозитов $\mathrm{Co}_{x}\left(\mathrm{MgF}_{2}\right)_{100-x}$ разного состава на ситаловых подложках. Справа приведены значения $x$, соответствующие содержанию металлического Со в атомных процентах. Две нижние дифрактограммы от поликристаллического порошка $\mathrm{MgF}_{2}$ и ситаловой подложки, верхняя - от металлической фольги $\alpha$-Сo. Три числа на верхней дифрактограмме соответствуют: верхний ряд - межплоскостные расстояния в ангстремах; средний ряд - относительные интенсивности в процентах; нижний ряд - индексы плоскостей.

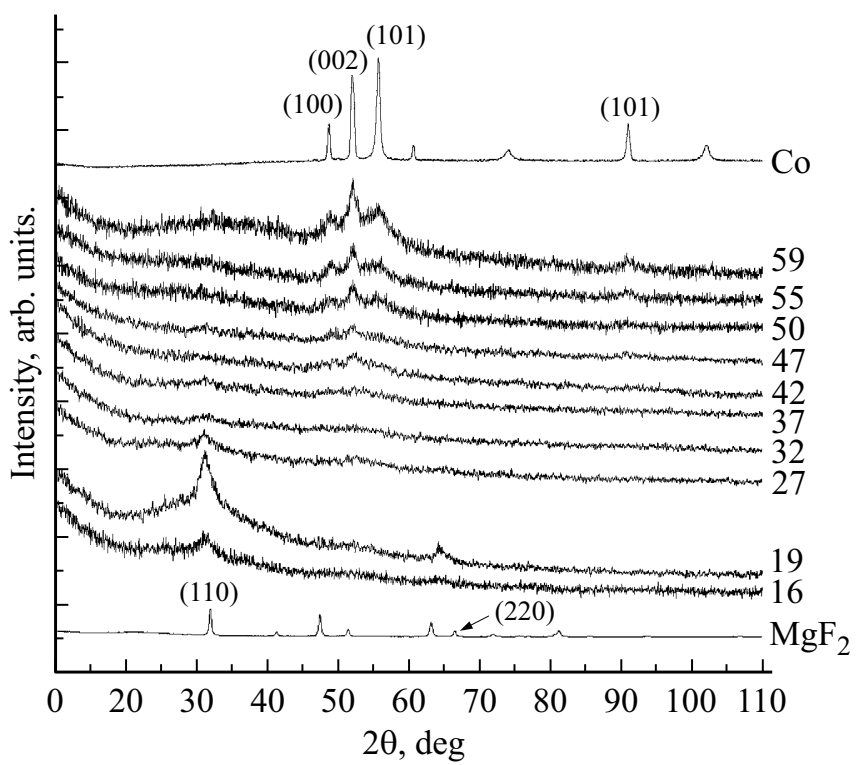

Рис. 2. Дифрактограммы от образцов нанокомпозитов $\mathrm{Co}_{x}\left(\mathrm{MgF}_{2}\right)_{100-x}$ разного состава на стеклянных подложках. Справа приведены значения $x$, соответствующие содержанию металлического Со в атомных процентах. Нижняя дифрактограмма получена от поликристаллического порошка $\mathrm{MgF}_{2}$, верхняя - от металлической фольги $\alpha$-Сo. 
Таблица 1. Значения межплоскостных расстояний образцов нанокомпозитов $\mathrm{Co}_{x}\left(\mathrm{MgF}_{2}\right)_{100-x}$ в сравнении с данными из базы данных PDF 2012 для $\alpha$-Co, $\mathrm{MgF}_{2}$ и $\mathrm{CoF}_{2}$

\begin{tabular}{l|c|c|c|c|c|c}
\hline \multicolumn{1}{c|}{ Образец } & $d_{(110)}, \AA$ & $d_{(100)}, \AA$ & $d_{(002)}, \AA$ & $d_{(101)}, \AA$ & $d_{(220)}, \AA$ & $d_{(110)}, \AA$ \\
\hline $\mathrm{Co}_{16}\left(\mathrm{MgF}_{2}\right)_{84}$ & $\mathbf{3 . 3 2 8}$ & & & & 1.679 & \\
$\mathrm{Co}_{19}\left(\mathrm{MgF}_{2}\right)_{81}$ & $\mathbf{3 . 3 4 4}$ & & & & 1.684 & \\
$\mathrm{Co}_{27}\left(\mathrm{MgF}_{2}\right)_{73}$ & $\mathbf{3 . 3 4 7}$ & & 2.022 & & 1.68 & \\
$\mathrm{Co}_{42}\left(\mathrm{MgF}_{2}\right)_{58}$ & & & $\mathbf{2 . 0 2 2}$ & & & \\
$\mathrm{Co}_{47}\left(\mathrm{MgF}_{2}\right)_{53}$ & & 2.15 & $\mathbf{2 . 0 4 2}$ & 1.92 & & 1.25 \\
$\mathrm{Co}_{50}\left(\mathrm{MgF}_{2}\right)_{50}$ & & 2.15 & $\mathbf{2 . 0 4 2}$ & 1.92 & & 1.25 \\
$\mathrm{Co}_{55}\left(\mathrm{MgF}_{2}\right)_{45}$ & & 2.16 & $\mathbf{2 . 0 4 2}$ & 1.92 & & 1.25 \\
$\mathrm{Co}_{59}\left(\mathrm{MgF}_{2}\right)_{41}$ & & 2.16 & $\mathbf{2 . 0 4 0}$ & 1.92 & & 1.25 \\
$\alpha-\mathrm{Co}_{2} 6_{3} / m m c[17]$ & & 2.169 & 2.035 & $\mathbf{1 . 9 1 4}$ & & 1.250 \\
$\mathrm{CoF}_{2} P 4_{2} m m m[18]$ & $\mathbf{3 . 3 3 2}$ & & & & & \\
$\mathrm{MgF}_{2} P 4_{2} m n m[19]$ & $\mathbf{3 . 2 6 8}$ & & & & &
\end{tabular}

за. Верхняя дифрактограмма на рисунках получена от поликристаллического образца металлического кобальта $\alpha$-Со гексагональной сингонии, а нижняя - от порошка $\mathrm{MgF}_{2}$, из которого изготовлены вставки в металлическую мишень.

Уже с первого взгляда на рис. 1 и 2 становится ясно, что практически все основные линии диэлектрической компоненты $\mathrm{MgF}_{2}$ и ситаловой подложки совпадают, поэтому рентгенодифракционный анализ фазового состава и субструктуры удобнее проводить с образцами на стеклянных подложках, рентгенограммы которых приведены на рис. 2. В табл. 1 приведены межплоскостные расстояния исследуемых композитов вместе с данными для фаз $\mathrm{MgF}_{2}, \mathrm{CoF}_{2}$ и поликристаллического Со из международной базы дифракционных данных The International Centre for Diffraction Data, PDF release 2012. Значения межплоскостных расстояний самых интенсивных линий экспериментальных дифрактограмм композитов $\mathrm{Co}_{x}\left(\mathrm{MgF}_{2}\right)_{100-x}$ и фаз сравнения из базы данных отмечены в табл. 1 жирным шрифтом.

Анализ дифрактограмм, представленных на рис. 2, и их сравнение со значениями из базы данных (табл. 1) показывает, что при малом содержании в композитах металлического кобальта на подложке происходит формирование нанокристаллической фазы. Об этом свидетельствует наличие в композите $\mathrm{Co}_{19}\left(\mathrm{MgF}_{2}\right)_{81}$ дифракционной линии с межплоскостным расстоянием $d=3.344 \AA$ на фоне широкого гало в области $2 \theta=22-45^{\circ}$. Полученное значение $d=3.344 \AA$ от нанокристаллической фазы ближе к соответствующему значению поликристаллического $\mathrm{CoF}_{2}$, нежели к $\mathrm{MgF}_{2}$. Однако, прежде чем делать поспешный вывод об образовании в композите фазы $\mathrm{CoF}_{2}$, следует принять во внимание возможное изменение величины $d$ в нанокристаллах тройной системы по сравнению с микрокристаллами бинарных соединений $\mathrm{MgF}_{2}$ и $\mathrm{CoF}_{2}$. Кроме того, представляется маловероятным, чтобы в условиях процессов самоорганизации, протекающих при формировании композита в условиях совместного осаждения атомов кобальта, магния и фтора на подложку, происходило бы образование энергетически менее выгодной фазы. Известно, что стандартная энтальпия образования $\mathrm{MgF}_{2}$ по модулю почти в два раза больше, чем энтальпия образования $\mathrm{CoF}_{2}(-1113 \mathrm{~kJ} / \mathrm{mol}$ и $-665 \mathrm{~kJ} / \mathrm{mol}$ соответственно) [20] Поэтому однозначно ответить на вопрос об образовании в композитах с малым содержанием кобальта фазы $\mathrm{CoF}_{2}$ на основании только лишь данных XRD не представляется возможным. К тому же, с увеличением концентрации Со дифракционная линия (110) постепенно исчезает, поскольку диэлектрическая фаза композита $\mathrm{MgF}_{2}$ становится аморфной.

Кроме того, уже начиная с $x=19$ at.\% и до $x=37$ at.\% на дифрактограммах рис. 2 просматривается гало при $2 \theta=53^{\circ}$, соответствующее положению максимума второй по интенсивности линии (002) поликристаллического гексагонального Со.

С дальнейшим увеличением содержания металла в композите $\mathrm{Co}_{x}\left(\mathrm{MgF}_{2}\right)_{100-x} \quad(x=42$ at.\% на ситаловой подложке и $x=29$ at.\% на стеклянной подложке) начинают формироваться нанокристаллы Со гексагональной сингонии. Однако даже с увеличением содержания Со до $x=59$ at.\% самым интенсивным остается отражение (002), но не (101), как в поликристаллическом металлическом образце $\alpha$-Сo, что может быть связано с преимущественной ориентацией нанокристаллов Со композита в направлении, перпендикулярном плоскости базиса гексагональной решетки.

В связи с малой интенсивностью и размытой формой рефлексов композитов $\mathrm{Co}_{x}\left(\mathrm{MgF}_{2}\right)_{100-x}$ величины их межплоскостных расстояний $d$ приведены в табл. 1 с точностью до второго знака, кроме самой интенсивной линии (002), межплоскостное расстояние $d$ которой определено с точностью до третьего знака. Сравнение полуширины этой линии (002) с полушириной аналогичной линии поликристаллического образца $\alpha$-Сo 
позволило оценить средние размеры нанокристаллов $L$ в композитах со значениями $x=42-59$ at.\% в соответствии с формулой Дебая-Шерера

$$
L=\frac{\lambda}{\beta \cos \theta},
$$

где $\beta=\sqrt{B^{2}-b^{2}}, B-$ полуширина дифракционной линии образца, $b$ - полуширина дифракционной линии эталона (в данном случае поликристаллического Со); $k$ - коэффициент, равный $0.9 ; \lambda-$ длина волны $\mathrm{CoK}_{\alpha}(1.789 \AA) ; \theta-$ угол дифракции отражения линии (002).

Произведенные оценки показали, что с увеличением содержания кобальта в композитах происходит заметное увеличение размеров нанокристаллов от $10 \mathrm{~nm}$ при $x=42$ at.\% до $20 \mathrm{~nm}$ при $x=59$ at.\%. Кроме того, внимательное рассмотрение значений межплоскостных расстояний образцов $\mathrm{Co}_{x}\left(\mathrm{MgF}_{2}\right)_{100-x}$ в сравнении с поликристаллическим Со и данными для Со из базы данных PDF2012 [17] показывает, что с увеличением размеров нанокристаллов величины их межплоскостных расстояний $d$ приближаются к соответствующим значениям поликристаллических образцов.

Следует отметить, что формирование нанокристаллов кобальта в аморфной диэлектрической матрице $\mathrm{MgF}_{2}$ на ситаловой подложке происходит при относительно меньшем содержании металла по сравнению со стеклянной подложкой, а именно, начиная с $x=29$ at.\% (сравнить рис. 1 и рис. 2)

\subsection{XPS-исследования нанокомпозитов $\mathrm{Co}_{x}\left(\mathrm{MgF}_{2}\right)_{100-x}$}

В основе метода рентгеновской фотоэлектронной спектроскопии XPS лежит переход связанного электрона с остовного уровня или из валентной зоны в свободное состояние посредством возбуждающих моноэнергетических фотонов. Поскольку энергии связи электронов в атомах твердого тела хорошо известны (табулированы) и различны для каждого элемента, их измерение позволяет определить химический состав поверхности различных материалов по изменению энергии связи данного элемента.

Энергия связи может быть определена по отношению к общему уровню Ферми материала $\Phi_{\text {spec }}$ спектрометра из соотношения

$$
E_{B}=h v-E_{\mathrm{kin}}-\Phi_{\mathrm{spec}}
$$

Обычно величина $\Phi_{\text {spec }}$ считается неизменной и учитывается по измерению энергии связи реперной линии. В качестве реперной линии нами, как обычно, использована линия $\mathrm{C} 1 s$ естественных углеводородных загрязнений поверхности образцов, не подвергнутых специальной очистке, приведенная к энергии $E_{B}^{\mathrm{Cls}}=285 \mathrm{eV}$. Энергии остовных уровней элементов сильно зависят от степени окисления и могут меняться в пределах нескольких $\mathrm{eV}$.
Этот эффект называется химическим сдвигом, который зависит от химического окружения атомов данного элемента и является результатом изменений в кулоновском и обменном потенциалах.

Исследование образцов методом XPS проводилось квантами характеристического излучения $\mathrm{A} 1 K_{\alpha}$. Диаметр рентгеновского зонда составлял $500 \mu \mathrm{m}$. Обработка экспериментальных данных, определение фоновой линии и ее вычитание в соответствии с алгоритмами Ширли [21] реализованы с использованием программного обеспечения прибора ESCALAB 250.

Идентификация остовных уровней XPS и химического состояния элементов были выполнены с использованием базы данных рентгеновских фотоэлектронных спектров Национального Института стандартов и технологий США [22].

В системе композитов $\mathrm{Co}_{x}\left(\mathrm{MgF}_{2}\right)_{100-x}$ были исследованы четыре образца разного состава $(x=14,19,54$ и 63 at.\%), нанесенные на ситаловые подложки. Поскольку при ионном травлении образцов по мере удаления от поверхности изменялись только спектры XPS остовных уровней $\mathrm{Co} 2 p$ и $\mathrm{O} 1 s$, то именно они и приведены в зависимости от времени травления для всех исследованных образцов на рис. 3 и 4. Каждый спектр получался на разных глубинах в 8-10 точках. На рис. 3 и 4 приведены $\mathrm{Co} 2 p$ и $\mathrm{O} 1 s$ спектры для исходной поверхности образца (начальной точки съемки), средних точек и конечных точек ионного травления. Конечная точка определялась таким образом, чтобы в последовательной серии спектров XPS Co $2 p$ практически не изменял свою форму. Для двух образцов ( $x=14$ at.\% и $x=63$ at.\%) последняя по глубине точка съемки получалась при 6 min травления, а для образцов $(x=19$ at.\% и $x=54$ at.\%) при $10 \mathrm{~min}$ травления. Все необходимые сведения об изменениях химических связей кобальта Со и кислорода по глубине образцов приведены на рис. 3 и 4.

Анализ тонкой структуры спектров рис. 3 показывает, что на поверхности композитных слоев кобальт сильно окислен во всех образцах, о чем свидетельствует преобладающая по интенсивности высокоэнергетическая компонента XPS Co2p с энергией связи $E=781.0 \mathrm{eV}$. Однако парадоксальным оказывается тот факт, что на поверхности образцов с малым содержанием Со $(x=14$ и 19 at.\%) обнаруживается компонента с энергией связи $E=778.0 \mathrm{eV}$ от металлического кобальта, который в этих образцах находится в мелкодисперсном состоянии в виде малых кластеров. После травления интенсивность компоненты оксида кобальта в спектрах XPS Co2p всех образцов быстро уменьшается, однако полностью удалить оксид не удается, о чем свидетельствует сравнение $\mathrm{Co} 2 p$ спектров протравленных композитов с $\mathrm{Co} 2 p$ спектрами металлического кобальта, приведенными на том же рис. 3.

Как показывают O1s спектры образцов с малым содержанием Со ( $x=14$ и 19 at.\%, рис. 4) при ионном травлении количество адсорбированного на поверхности 

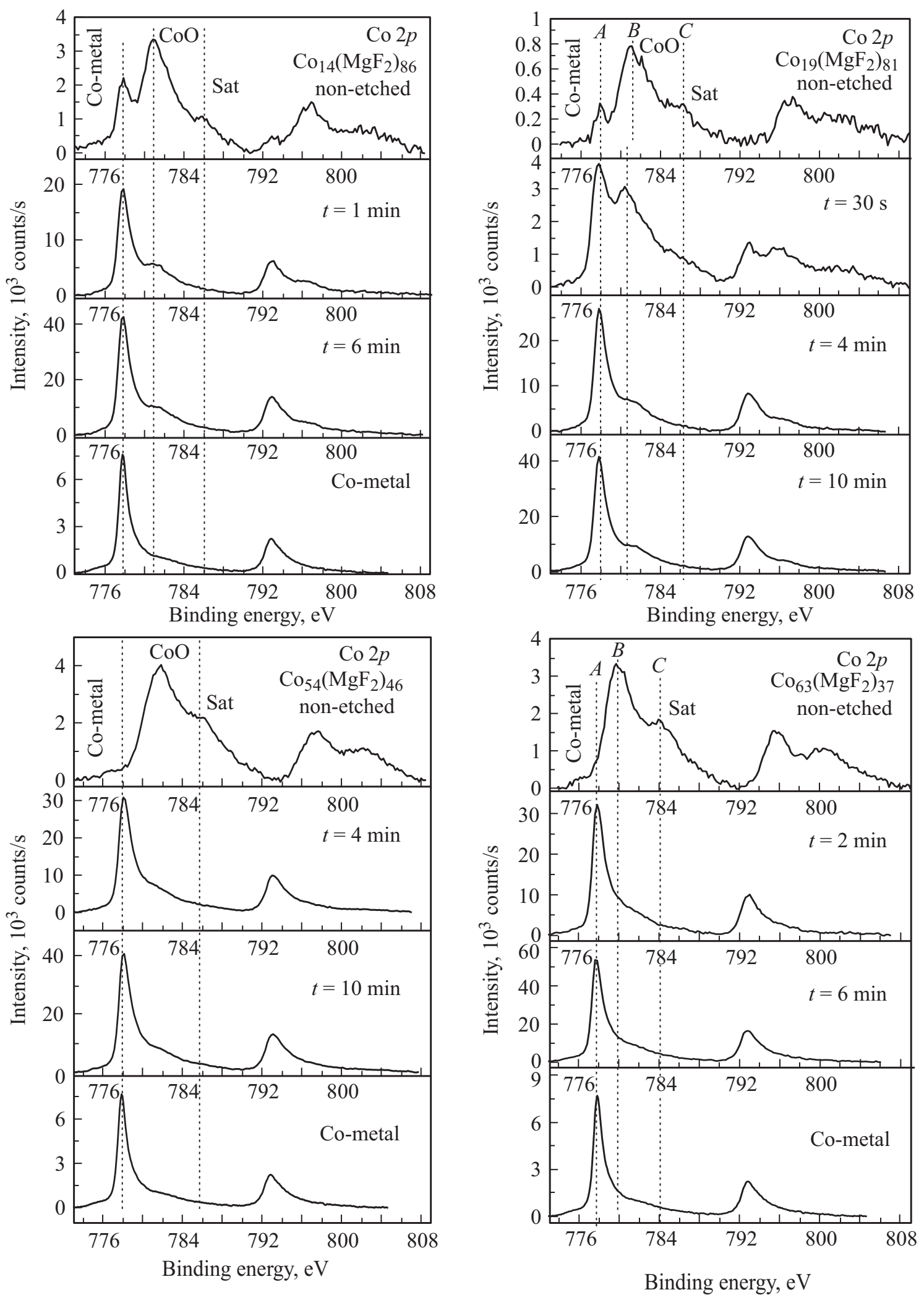

Pис. 3. Рентгеноэлектронные спектры XPS Co $2 p_{1 / 2,3 / 2}$ в нанокомпозитах $\mathrm{Co}_{x}\left(\mathrm{MgF}_{2}\right)_{100-x}$ разного состава на ситаловых подложках.

кислорода, ОН групп и молекул $\mathrm{H}_{2} \mathrm{O}$ быстро уменьшается, и остается, в основном, кислород, типичный для оксида $\mathrm{CoO}$ с энергией связи $E=529.7-531.4 \mathrm{eV}$. По видимому, этот оксид находится на поверхности металлических нанокластеров. С таким эффектом мы часто сталкиваемся в поликристаллических металлах. Там при 

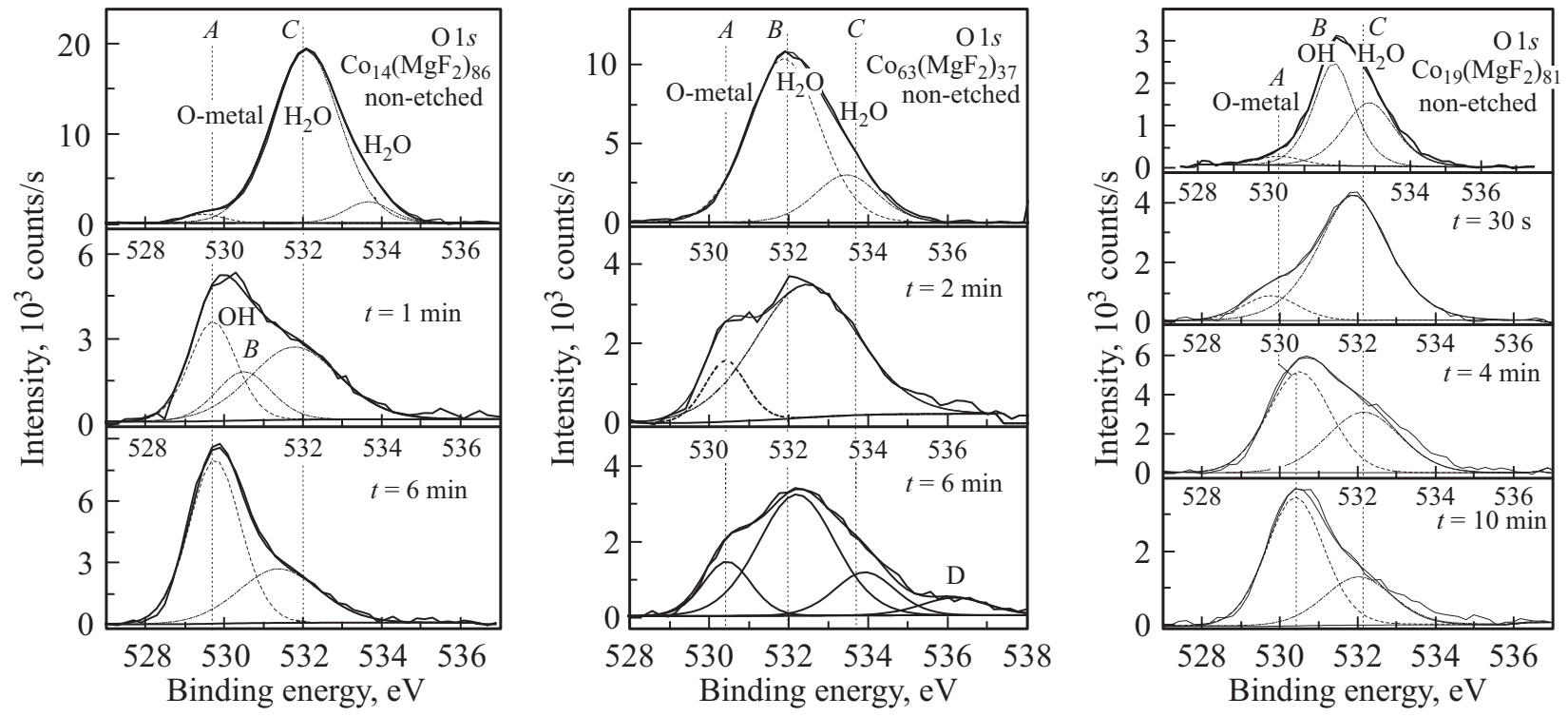

Pис. 4. Рентгеноэлектронные спектры XPS O $1 s$ в нанокомпозитах $\mathrm{Co}_{x}\left(\mathrm{MgF}_{2}\right)_{100-x}$ разного состава на ситаловых подложках.
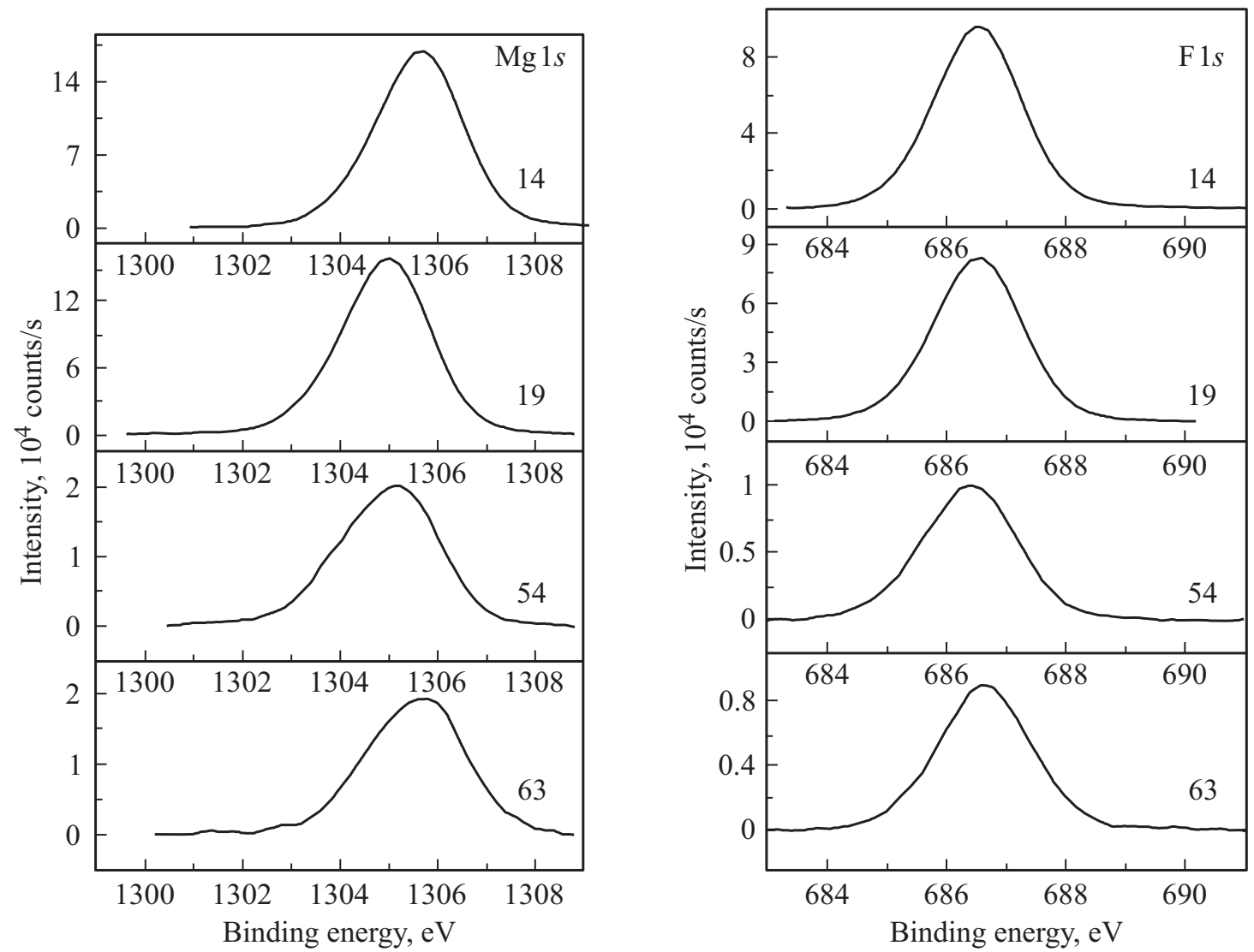

Рис. 5. Рентгеноэлектронные спектры XPS $\mathrm{Mg} 1 s$ и $\mathrm{F} 1 s$ в нанокомпозитах $\mathrm{Co}_{x}\left(\mathrm{MgF}_{2}\right)_{100-x}$ разного состава на ситаловых подложках.

длительном травлении содержание кислорода приближается, примерно, к 5 at.\%. Этот кислород расположен на межзеренных границах. Аналогичная ситуация наблюдается и в образцах с малым содержанием кобальта.
Как видно из приведенной табл. 2 содержание кислорода в последнем исследованном слое этих композитов составляет около 5-6at.\%. Таким образом, даже в случае использования бескислородных диэлектриче- 
Таблица 2. Элементный состав последних по глубине исследованных слоев нано композитов $\mathrm{Co}-\mathrm{MgF}_{2}$ (в at.\%). (С учетом и без учета углеродного пика)

\begin{tabular}{|c|c|c|c|c|c|c|}
\hline $\begin{array}{c}\text { Содержание } \\
\text { Со в образцах }\end{array}$ & $\begin{array}{c}\text { Время } \\
\text { травления, } \\
\text { min }\end{array}$ & $\mathrm{C}$ & Co & $\mathrm{F}$ & $\mathrm{Mg}$ & $\mathrm{O}$ \\
\hline$x=14$ & 6 & $\begin{array}{c}5.65 \\
-\end{array}$ & $\begin{array}{l}9.21 \\
9.76\end{array}$ & $\begin{array}{l}32.82 \\
34.78\end{array}$ & $\begin{array}{l}46.86 \\
49.67\end{array}$ & $\begin{array}{l}5.46 \\
5.79\end{array}$ \\
\hline$x=19$ & 10 & $\begin{array}{c}8.69 \\
-\end{array}$ & $\begin{array}{l}8.72 \\
9.55\end{array}$ & $\begin{array}{l}30.53 \\
33.44\end{array}$ & $\begin{array}{l}46.68 \\
51.12\end{array}$ & $\begin{array}{l}5.38 \\
5.89\end{array}$ \\
\hline$x=54$ & 10 & $\begin{array}{c}46.47 \\
-\end{array}$ & $\begin{array}{l}18.95 \\
35.72\end{array}$ & $\begin{array}{r}8.61 \\
15.98\end{array}$ & $\begin{array}{l}17.48 \\
32.47\end{array}$ & $\begin{array}{r}8.49 \\
15.83\end{array}$ \\
\hline$x=$ & 6 & $\begin{array}{c}41.93 \\
-\end{array}$ & $\begin{array}{l}24.13 \\
41.56\end{array}$ & $\begin{array}{r}7.94 \\
13.67\end{array}$ & $\begin{array}{l}17.91 \\
30.84\end{array}$ & $\begin{array}{r}8.09 \\
13.93\end{array}$ \\
\hline
\end{tabular}

ских матриц при формировании композитов вакуумными методами (ионным распылением мишеней) поверхность металлических гранул оказываются незначительно окисленной. По всей видимости, это является следствием диффузии кислорода с поверхности по межфазным границам, которые в случае нанокомпозитов занимают существенную часть объема материала.

Следует особо отметить, что по данным XPS, взаимодействия кобальта с фтором в системе $\mathrm{Co}_{x}\left(\mathrm{MgF}_{2}\right)_{100-x}$ не обнаружено. XPS остовных уровней $\mathrm{Mg} 2 p$ и $\mathrm{F} 1 s$ диэлектрической компоненты $\mathrm{MgF}_{2}$ во всех образцах, приведенные на рис. 5, имеют энергии связей, характерные для фазы $\mathrm{MgF}_{2}$ [22]: $E(\mathrm{Mg} 1 s)=1305.0-1306.0 \mathrm{eV}$ и $E(\mathrm{~F} 1 s)=686.5 \mathrm{eV}$.

Таким образом, в соответствии с результатами XRDи XPS-исследований образцов с малым содержанием кобальта, можно утверждать, что диэлектрическая матрица этих композитов формируется из нанокристаллов $\mathrm{MgF}_{2}$ с несколько увеличенными межатомными/межплоскостными расстояниями по сравнению с микрокристаллами $\mathrm{MgF}_{2}$ [19]. По мере увеличения концентрации кобальта с образованием металлических нанокристаллов размер нанокристаллов матрицы $\mathrm{MgF}_{2}$ уменьшается и выходит за пределы чувствительности метода рентгеновской дифракции, а сама фторидная фаза становится таким образом рентгеноаморфной. В результате при любом составе образцов, по крайней мере, в пределах исследованного интервала, композит состоит из рентгеноаморфной и нанокристаллической фаз. Условным порогом образования нанокристаллической фазы кобальта в композитах $\mathrm{Co}_{x}\left(\mathrm{MgF}_{2}\right)_{100-x}$, нанесенных на ситаловые подложки, можно считать значение $x=29$ at.\%, а на стеклянные подложки значение $x=42$ at.\%, при которых начинает идентифицироваться дифракционный пик от металлической фазы со средними размерами нанокристаллов кобальта $\sim 10 \mathrm{~nm}$, увеличивающимися до $\sim 20 \mathrm{~nm}$ вблизи порога перколяции.

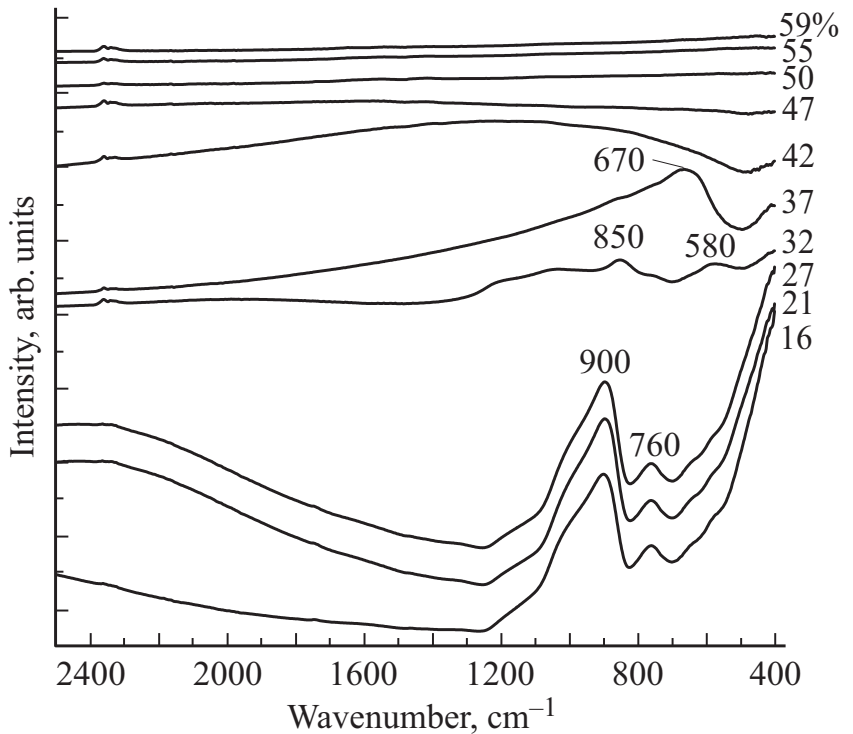

Рис. 6. ИК-спектры образцов нанокомпозитов $\mathrm{Co}_{x}\left(\mathrm{MgF}_{2}\right)_{100-x}$ разного состава на стеклянных подложках.

\section{3. ИК-спектры нанокомпозитов $\mathrm{Co}_{x}\left(\mathrm{MgF}_{2}\right)_{100-x}$}

Метод ИК-спектроскопии позволяет получить сведения о связи между элементами в композите [23], что является принципиально важным при изучении структурно-информационных свойств различных веществ. На рис. 6 представлены ИК-спектры композитов $\mathrm{Co}_{x}\left(\mathrm{MgF}_{2}\right)_{100-x}$ тех же составов, для которых проводились XRD и XPS исследования. ИК-спектры регистрировались в геометрии на отражение методикой НПВО - нарушенного полного внутреннего отражения в интервале $400-2400 \mathrm{~cm}^{-1}$.

Результаты, представленные на Рис.6, показывают, что информативной является область $400-1400 \mathrm{~cm}^{-1}$, в которой происходит наиболее четкое формирование мод диэлектрической матрицы $\mathrm{MgF}_{2}$ на ИК-спектрах образцов с наименьшим содержанием металлической фазы в диапазоне $x=16-27$ at.\%. Полученные значения частот мод на ИК-спектрах от композитов этих составов, приведенные в табл. 3, согласуются с данными для фазы $\mathrm{MgF}_{2}$ из монографии по ИК-спектрам неорганических соединений [24].

Таблица 3. Частоты характеристических колебаний нанокомпозитов $\mathrm{Co}_{x}\left(\mathrm{MgF}_{2}\right)_{100-x}$ и $\mathrm{MgF}_{2}$

\begin{tabular}{c|c|c|c|c|c}
\hline Образец & \multicolumn{5}{|c}{ Волновое число } \\
\hline $\mathrm{Co}_{16}\left(\mathrm{MgF}_{2}\right)_{84}$ & & 670 & 760 & & 900 \\
$\mathrm{Co}_{21}\left(\mathrm{MgF}_{2}\right)_{79}$ & & 670 & 760 & & 900 \\
$\mathrm{Co}_{27}\left(\mathrm{MgF}_{2}\right)_{73}$ & & 670 & 760 & & 900 \\
$\mathrm{Co}_{32}\left(\mathrm{MgF}_{2}\right)_{68}$ & 580 & 670 & 760 & 850 & \\
$\mathrm{Co}_{37}\left(\mathrm{MgF}_{2}\right)_{63}$ & & 670 & & & \\
$\mathrm{MgF}_{2}[24]$ & & 675 & 725 & 875 & 920
\end{tabular}


По крайней мере, три из обнаруженных мод композитов близки к значениям мод $\mathrm{MgF}_{2}$, приведенных в [24]. Некоторые изменения частот мод по сравнению с литературными [24] могут быть обусловлены малыми размерами нанокристаллов диэлектрической матрицы $\mathrm{MgF}_{2}$, содержащей кластеры металлического кобальта.

С увеличением содержания в образцах металлической компоненты, приводящим к формированию нанокристаллов Сo, начиная с $x=42$ at.\% в образцах на стеклянной подложке, происходит полное отражение ИК-излучения от поверхности образцов, и на ИК-спектрах проявляются лишь слабые моды $\mathrm{CO}_{2}$. в области $\sim 2350 \mathrm{~cm}^{-1}$.

\section{4. Заключение}

Полученные результаты комплексных исследований композитов $\mathrm{Co}_{x}\left(\mathrm{MgF}_{2}\right)_{100-x}$ методами XRD, XPS и ИК-спектроскопии показали, что относительное содержание металлического кобальта Со в диэлектрической матрице $\mathrm{MgF}_{2}$ существенным образом влияет не только на его субструкуру, но и на состояние диэлектрической матрицы. При малом содержании Со (менее 29 at.\% на ситаловой подложке и менее 42 at.\% на стеклянной подложке) он находится в виде рентгеноаморфных кластеров, распределенных в объеме нанокристаллической матрицы $\mathrm{MgF}_{2}$.*

На ИК-спектрах образцов этих составов наблюдаются наиболее выраженные моды от нанокристаллической диэлектрической фазы $\mathrm{MgF}_{2}$. C увеличением содержания кобальта до 29 at.\% в композитах, напыленных на ситалловую подложку, и до $x=42$ at.\% в композитах на стеклянной подложке, формируются нанокристаллы кобальта гексагональной сингонии размерами порядка $10 \mathrm{~nm}$, преимущественно ориентированные в плоскости базиса гексагональной решетки (002) $\alpha$-Со. При дальнейшем возрастании содержания кобальта в композите до $x=59$ at.\% размеры нанокристаллов $\alpha$-Со уже в рентгеноаморфной матрице $\mathrm{MgF}_{2}$ достигают $\sim 20 \mathrm{~nm}$ c сохранением той же преимущественной ориентации. Таким образом, в пределах исследованного интервала изменения составов $x=14-63$ at.\% композит состоит из рентгеноаморфной и нанокристаллической фазы. Какая из двух компонент, металлическая (Со) или диэлектрическая $\left(\mathrm{MgF}_{2}\right)$, образует нанокристаллы, определяется некоторой критической величиной ее содержания в композите, зависимой от термодинамических условий самоорганизации многокомпонентной системы, на которую в числе многих факторов влияет и материал подложки.

Тонкая структура спектров XPS Co $2 p$ и О $1 s$ показала, что на поверхности композитов кобальт сильно окислен при всех составах композита, и только на поверхности образцов с малым содержанием Со рентгеноаморфный кобальт обнаруживается в металлическом состоянии наряду с оксидом кобальта. В объеме нанокомпозитов также обнаруживается незначительное количество атомов кислорода, что, по-видимому, является следствием его диффузии по межфазным границам и окислением поверхности металлических кластеров и нанокристаллов.

\section{Список литературы}

[1] С.А. Гриднев, Ю.Е. Калинин, А.В. Ситников, О.В. Стогней. Нелинейные явления в нано- и микрогетерогенных системах. БИНОМ. Лаборатория знаний. М. (2012). 352 с.

[2] M.N. Baibich, T.M. Broto, A. Fert, F. Nguen Van Dau, F. Petroff, P. Etienne, G. Creuset, A. Friedrich, T. Chazelas. Phys. Rev. Lett. 61, 2472 (1988).

[3] A.E. Berkowitz, T.R. Mitchell, M.T. Carey, A.P. Young, S. Zhang, F.E. Spada, F.T. Parker, A. Hutten, G. Thomas. Phys. Rev. Lett. 68, 3745 (1992).

[4] J.Q. Xiao, J.S. Jiang, C.L. Chien. Phys. Rev. Lett. 68, 3749 (1992).

[5] P.M. Levy. Solid State Phys. 47, 369 (1994).

[6] T. Miyazaki, N. Tezuka. J. Magn. Magn. Mater. 139, L231 (1995).

[7] J.S. Moodera, L.R. Kinder, T.M. Wong, R. Meservey. Phys. Rev. Lett. 74, 3273 (1995).

[8] H. Fujimori, S. Mitani, S. Ohnuma. Mater. Sci. Eng., B 31, 219 (1995).

[9] H. Fujimori, S. Mitani, S. Ohnuma. J. Magn. Magn. Mater. 156, 311 (1996).

[10] S. Maekawa, U. Gafvert. IEEE Trans. Magn. 18, 707 (1982).

[11] О.В. Стогней. Электроперенос и магнитные свойства аморфных наногранулированных композитов металлдиэлектрик. Докт. дисс. ВГТУ, Воронеж (2004). 280 с.

[12] Nobukiyo Kobayashi, Shigehiro Ohnuma, Tsuyoshi Masumoto, Hiroyasu Fujimori. J. Appl. Phys. 90 8, 4159 (2001).

[13] Dongsheng Yao, Shihui Ge, Bangmin Zhang, Huaping Zuo, Xueyun Zhou. J. Appl. Phys. 103, 113901 (2008). DOU: $10.1063 / 1.2932076$

[14] S. Sankar, A.E. Berkowitz, D.J. Smith. Phys. Rev. B 62, 14273 (2000).

[15] О.В. Стогней, А.В. Ситников, Ю.Е. Калинин, С.Ф. Авдеев, М.Н. Копытин. ФТТ 49, 158 (2007).

[16] О.В. Стогней, Ю.Е. Калинин, А.В. Ситников. ФММ 91, 21 (2006).

[17] The International Centre for Diffraction Data, PDF release 2012. 01-077-7453.

[18] The International Centre for Diffraction Data, PDF release 2012. 01-087-0722.

[19] The International Centre for Diffraction Data, PDF release 2012. 01-070-2498.

[20] А.И. Ефимов, Л.П. Белорукова, И.В. Василькова, В.П. Чечев. Свойства неорганических соединений. Справочник. Химия, Л. (1983). 153 с.

[21] D.A. Shirley. Phys. Rev. B 5, 4709 (1972).

[22] X-ray NIST Photoelectron Spectroscopy Database, $\langle$ http://srdata.nist.gov/xps $\rangle$.

[23] Э.П. Домашевская, Н.С. Буйлов, В.А. Терехов, К.И. Барков, В.Г. Ситников. ФТТ 59, 161 (2017).

[24] A.R. Nyquist, R.O. Kagel. Infrared spectra of inorganic compounds. Academic Press. N. Y.-London. (1971). 499 p.

Редактор Ю.Э. Китаев 